\title{
Involvement of medical students in a surgery congress: impact on learning motivation, decision-making for a career in surgery, and educational curriculum
}

\author{
Ibrahim Alkatout · Veronika Günther · Sandra Brügge · Johannes Ackermann · Magret Krüger · Dirk Bauerschlag · \\ Nicolai Maass · Sebastian Lippross · Ingolf Cascorbi · Jan-Hendrik Egberts · Thomas Becker · Daniar Osmonov · \\ Klaus-Peter Jünemann · Thilo Wedel
}

Received: 28 September 2020 / Accepted: 17 November 2020 / Published online: 14 January 2021

(C) The Author(s) 2021

Summary During the preclinical period of medical school, the clinical relevance of theoretical knowledge is given little attention. Medical students of the second year were invited to participate in an interdisciplinary congress for robot-assisted and digital surgery. The students had to evaluate the impact of the congress on their learning motivation, decision-making for a career in surgery, and relevance for their educational curriculum. Participation in the congress increased their learning motivation for preclinical subjects, and significantly increased their interest in a surgical career. Most students considered active involvement in medical congresses a valuable supplement to the medical curriculum. Congress participation during the preclinical period was ranked positively by medical students. Greater learning motivation and enthusiasm for the pilot teaching project

Ibrahim Alkatout, Veronika Günther, and Thilo Wedel contributed equally to the manuscript.

Availability of data and materials The datasets analyzed during the current study are available from the corresponding author on reasonable request.

Prof. Dr. med. I. Alkatout, M.A., MaHM ( $\varangle)$ · V. Günther · S. Brügge $\cdot$ J. Ackermann $\cdot$ M. Krüger $\cdot$ D. Bauerschlag . N. Maass

Department of Obstetrics and Gynecology, University

Hospitals Schleswig-Holstein, Campus Kiel,

Arnold-Heller-Str. 3, House C, 24105 Kiel, Germany

kiel.school@uksh.de

S. Lippross

Department of Trauma Surgery and Orthopaedics,

University Hospitals Schleswig-Holstein, Campus Kiel,

Arnold-Heller-Str. 3, 24105 Kiel, Germany

I. Cascorbi

Institute of Experimental and Clinical Pharmacology,

University Hospitals Schleswig-Holstein, Campus Kiel,

Arnold-Heller-Str. 3, 24105 Kiel, Germany as well as for surgical disciplines were registered. Thus, early involvement of medical students in scientific congresses should be an integral part of their educational curriculum.

Keywords Teaching project $\cdot$ Students $\cdot$ Minimally invasive surgery $\cdot$ Surgical career $\cdot$ Curriculum

Teilnahme von Medizinstudierenden an einem chirurgischen Kongress: Einfluss auf die Lernmotivation, die Entscheidung zu einer Karriere in der Chirurgie und den Lehrplan im Allgemeinen

Zusammenfassung In den vorklinischen Semestern des Medizinstudiums wird der klinischen Relevanz oft wenig Aufmerksamkeit geschenkt. Medizinstudieren-

\footnotetext{
J.-H. Egberts · T. Becker

Department of General-, Visceral-, Thoracic-, Transplant- and Paediatric Surgery, University Hospitals Schleswig-Holstein, Campus Kiel, Arnold-Heller-Str. 3, 24105 Kiel, Germany

D. Osmonov · K.-P. Jünemann

Department of Urology and Pediatric Urology,

University Hospitals Schleswig-Holstein, Campus Kiel, Arnold-Heller-Str. 3, 24105 Kiel, Germany

T. Wedel

Center for Clinical Anatomy, Institute of Anatomy, Christian-Albrechts-Universität zu Kiel, Otto-Hahn-Platz 8, 24118 Kiel, Germany
} 
de des zweiten Studienjahres wurden eingeladen, an einem interdisziplinären Kongress für robotergestützte und digitale Chirurgie teilzunehmen. Im Anschluss sollten die Studierenden den Einfluss des Kongresses auf ihre Lernmotivation, die Entscheidungsfindung für eine Karriere in einem chirurgischen Fach und die Relevanz für das Curriculum bewerten. Durch die Kongressteilnahme steigerte sich die Lernmotivation für vorklinische Fächer, und das Interesse an einer chirurgischen Laufbahn nahm erheblich zu. Die meisten Studierenden betrachteten die aktive Teilnahme an medizinischen Kongressen als wertvolle Ergänzung des Lehrplans für das Studium. Die Kongressteilnahme während der Vorklinik wurde sehr positiv bewertet. Es wurde eine größere Lernmotivation für das Medizinstudium sowie eine Begeisterung für das Pilot-Lehrprojekt und für die chirurgischen Disziplinen registriert. Daher sollte die frühzeitige Einbindung der Medizinstudenten in wissenschaftliche Kongresse ein integraler Bestandteil ihres Curriculums werden.

Schlüsselwörter Lehrprojekt · Studenten · Minimalinvasive Chirurgie · Chirurgische Karriere . Curriculum

\section{Background}

In most German medical schools, the curriculum is divided into a preclinical and a clinical period. The preclinical period (2 years) includes anatomy, physiology, and biochemistry as well as basic natural and social sciences such as biology, chemistry, physics, and medical sociology/psychology. The clinical period (4 years) covers all clinical subjects and familiarizes the student with the spectrum of conservative and surgical medical disciplines. The last year (sixth year) is the so-called practical year and is spent exclusively in teaching hospitals. While two trimesters have to be absolved in internal medicine and surgery, the clinical subject of the third trimester may be selected by the student.

In the USA, a student must obtain a bachelor's degree (4 years) before being accepted at a medical school. This pre-medical education does not necessarily have to be linked to medical science. The American curriculum at medical schools is also divided into a preclinical (2 years) and clinical (2 years) study period. In Great Britain, the first year of medical school covers anatomy, biochemistry, and physiology, while the second year is focused on basic clinical subjects such as pathology, pharmacology, and neurosciences. The third year is spent in elective periods and is concluded with a Bachelor of Arts degree. The fourth and fifth years address all relevant clinical subjects and are much more practice oriented than in Germany. The sixth/final year includes the consolidation of skills and prepares the student for clinical practice [1].
The rather strict division of the traditional medical curriculum into a preclinical and clinical period, as offered in most German medical schools, has a number of didactic disadvantages. Most preclinical subjects are taught and learned without major emphasis on clinical aspects. For example, during the dissection course in macroscopic anatomy, anatomical structures are not consistently linked to relevant surgical procedures and are frequently committed to memory without being given clinical context. Subsequently, the significance of anatomical facts acquired during the preclinical period will become evident rather late during the clinical study period or even during the student's residency [2]. Thus, there is an increasing need to bridge this gap by offering early insights into clinical applications of preclinical information. Highlighting these practical aspects is expected to enhance the students' learning motivation as well as helping them to become identified with their future professional careers. In this context, the link between anatomical and clinical topics is particularly relevant for surgical subjects, because a thorough knowledge of anatomy is indispensable for all surgical disciplines.

However, the decision in favor of a career in surgery has undergone a marked change during the last decade. There has been a steady decline in the number of medical students opting for a surgical career. The underlying reasons for this disillusioning process are multifactorial, but social changes associated with the currently dominant "generations $\mathrm{Y}$ and Z" may contribute substantially to this development [3]. These generations tend to refuse what they consider outdated hierarchies and expect a meaningful work-life balance. Surgical disciplines call for substantial physical effort and time in addition to a rather long learning curve, which makes surgery less attractive [4].

Moreover, it may be assumed that the next generation of surgeons will hardly experience the traditional open surgical techniques, but will be directly confronted with minimally invasive digital surgery. Over the past decade, many surgical interventions have been converted to the laparoscopic or robotic approach [5]. While training in surgery traditionally started with open-access procedures, these were followed by laparoscopic, pelviscopic, or thoracoscopic procedures. The new generation of surgeons frequently start their professional career by performing minimally invasive surgery and are thus facing more challenging scenarios [6]. Modern formats of surgical congresses have taken these challenges into account by offering practical hands-on workshops, virtualreality training, and tutorial video sessions or live surgeries to enhance surgical skills and education [7]. However, most congresses are confined to postgraduate education and provide limited options for medical students to be involved in their stimulating learning atmosphere. 
Based on these considerations, a pilot teaching project was launched by the Medical Faculty of Kiel University. Preclinical medical students of the second academic year were invited to participate in an interdisciplinary congress on robot-assisted and digital surgery. The congress covered major surgical interventions in the fields of urology, gynecology, and surgery by means of video lectures, live surgeries, and interdisciplinary discussions. The aim of the congress was to highlight the latest technical developments in laparoscopic and robot-assisted surgery. The event was held at the end of the preclinical dissection course of macroscopic anatomy, and was actively assisted by the staff of the Institute of Anatomy. The aims of this pilot teaching project were to evaluate the impact of preclinical medical students' participation in a surgical congress on their learning motivation and decision-making for a career in surgery, and to assess whether this concept could become an integral part of the educational curriculum.

\section{Methods}

\section{Participating medical students}

All medical students of the second academic year $(n=176)$ at the end of their preclinical period were officially invited to attend the congress on a voluntary basis. At the time of the convention they were in the final phase of their practical course in macroscopic anatomy, including supervised dissection of body donors and anatomy lectures. Based on the program, 2 weeks before the congress the students were asked to prepare written and illustrated excerpts of those anatomical regions which would then be presented and treated surgically during the congress. As these anatomical topics were also relevant for the upcoming written and oral examination at the end of the preclinical period, the effort was worthwhile for the students.

\section{Congress format}

The congress was the 11th symposium of the German Society for Robot-Assisted Urology (Deutsche Gesellschaft für Roboter-assistierte Urologiee. V., DRUS) and simultaneously the first interdisciplinary symposium for robot-assisted and digital surgery in urology, gynecology, and visceral surgery organized by the Kurt Semm Center at the University Hospital of Schleswig-Holstein in Kiel (June 5th-7th, 2019). The congress format was unconventional and innovative. Instead of a single surgical discipline, those anatomical regions (pelvis, retroperitoneum) which are of interest for all disciplines were addressed. The organizers aimed to exchange and discuss current options, developments, and potentials of minimally invasive techniques among the three major fields of surgery. Interactive lectures, video sessions, and live surgeries were presented by urologists, gynecologists, and visceral surgeons. All surgical procedures were performed on a minimally invasive basis either by the laparoscopic or robotic approach, and included the following operations: radical prostatectomy with extended lymphadenectomy, salvage lymphadenectomy after prostatectomy, colorectal resection with total mesorectal excision/complete excision of the mesocolon, total hysterectomy with para-aortal lymphadenectomy, and sacrocolpopexy.

\section{Pilot teaching project}

The intention to make the congress accessible to preclinical students was discussed in detail and planned at the Kurt Semm Center, Kiel School of Gynecological Endoscopy, and the Institute of Anatomy. The somewhat different format of the meeting was considered especially appropriate to address the pending issues outlined in the introduction: (1) to bridge the gap between preclinical theoretical knowledge and clinical application, (2) to induce enthusiasm for major surgical disciplines, (3) to establish early contact with minimally invasive and digital surgical techniques. Based on these considerations, the Medical Faculty of Kiel University funded this pilot teaching project to enable medical students to attend the congress free of charge. All chairmen and presenters were informed about the project well in advance, so that they could consider these special circumstances in their lectures, explanatory notes, and comments during live surgeries. The students attended all sessions of a full-day program instead of regular lectures at the university. They were also permitted to visit the industrial exhibition and become familiar with the latest technical innovations and simulator devices in the field of minimally invasive and robotic surgery. They were invited to approach the surgical faculty and other participants for further questions and networking. At the end of the congress the medical students were asked to fill in a questionnaire.

\section{Questionnaire}

The questionnaire recorded age, gender, and previous vocational training, and consisted of the following questions:

1. Did the congress increase your motivation to learn anatomy?

2. Were you able to follow the details of the individual surgical interventions?

3. How high was your interest in a professional career in surgery before the congress?

4. How high was your interest in a professional career in surgery after the congress?

5. How highly do you rate the educational gains of participating in a clinical congress as a medical student? 
6. Should the participation of medical students in clinical congresses be an integral part of the medical curriculum?

The questions could be answered on a five-point Likert scale consisting of the following items:

- no-rather no-neither yes nor no-rather yes-yes (questions 1, 2, 6)

- low-rather low-neither high nor low-rather high—very high (questions $3,4,5$ )

Moreover, the following questions could be answered in free text:

1. What did you particularly like about this teaching project?

2. What did you not like about this teaching project?

3. What would you improve in this teaching project?

\section{Methods}

Quantitative values were presented as means and standard deviations, minimum, maximum, and quartiles. They were tested for normal distribution using the Shapiro-Wilk test. Since the distribution of age showed significant deviations from the normal distribution, a non-parametric Kruskal-Wallis test was used to analyze questions 1 to 6 . Ordinally and nominally scaled values were displayed in absolute and percentage frequencies. Nominally scaled educational background and gender were compared with ordinally scaled answers to the questions in contingency tables, and were tested for association using the exact linear trend chi-square test. Bowker's symmetry test was used to compare the answers to questions 3 and 4 . The tests were two-sided, with a significance level of 5\%. Alpha adjustment for multiple testing was not performed, and the results were interpreted accordingly. SPSS Statistics 25 (SPSS Inc. an IBM
Company, Armonk, NY, USA) was used for statistical calculations.

\section{Results}

\section{Description of the participating medical students}

One-hundred and forty-three students attended the congress and filled in the questionnaire; 138 questionnaires were answered in full and used for further analysis. Ninety-eight students were female and their mean age was 23 years (range 19-36 years), Thirtynine students were male and their mean age was 23 years (range 19-29 years). One student did not indicate his/her gender. While $64.1 \%$ of students had directly entered medical school, $35.9 \%$ had already completed a vocational training. Most of these students had worked as hospital or scrub nurses (16.2\%) and emergency medical assistants (11.3\%), whereas the others had been involved in medical, laboratory, biological, or pharmaceutical activities (8.4\%).

\section{Analysis of questionnaires}

Answers to the six questions (five-point Likert scale) were analyzed separately for male and female students, and are shown in bar charts (Figs. 1, 2, 3, 4, 5 and 6$)$.

Question 1: Did the congress increase your motivation to learn anatomy?

$45.0 \%$ of female students and $43.6 \%$ of male students said "yes," while $34.0 \%$ of female students and $41.0 \%$ of male students said "rather yes" (Fig. 1).

Question 2: Were you able to follow the details of the individual surgical interventions?
Fig. 1 Responses to question 1: Did the congress increase your motivation to learn anatomy?

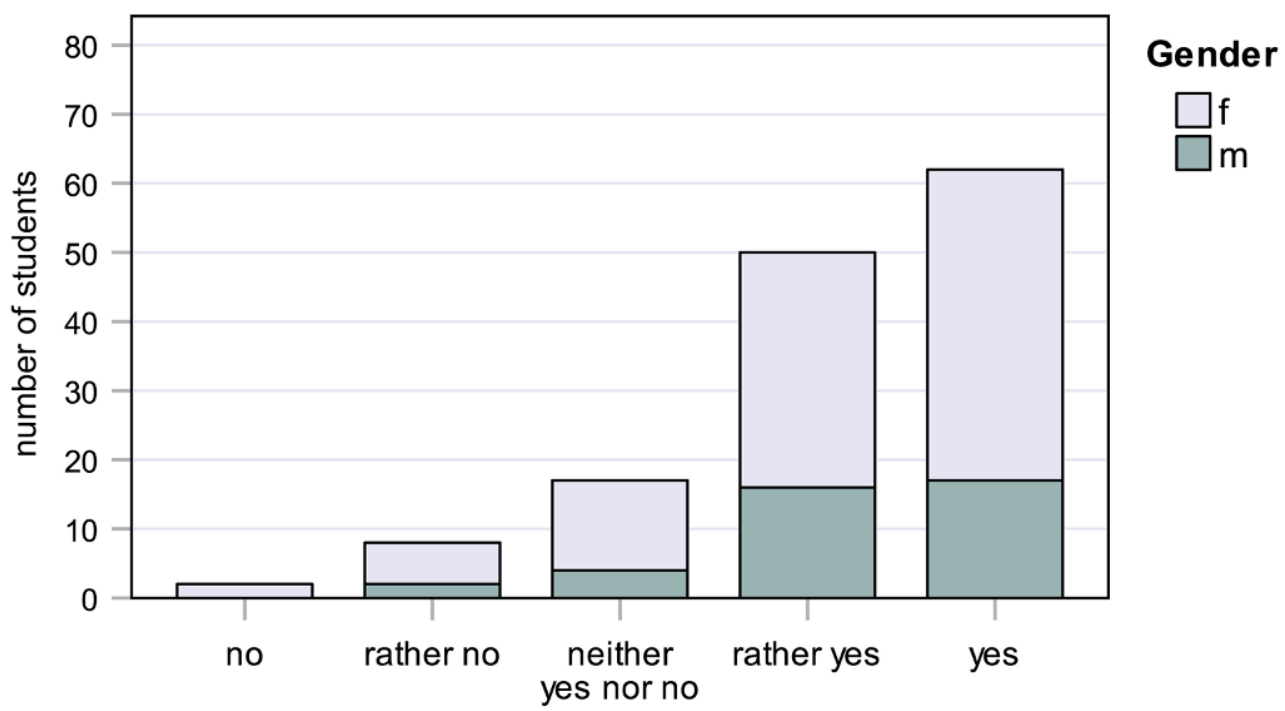

Did the congress increase your motivation to learn anatomy? 
Fig. 2 Responses to question 2: Were you able to follow the details of the surgical interventions?

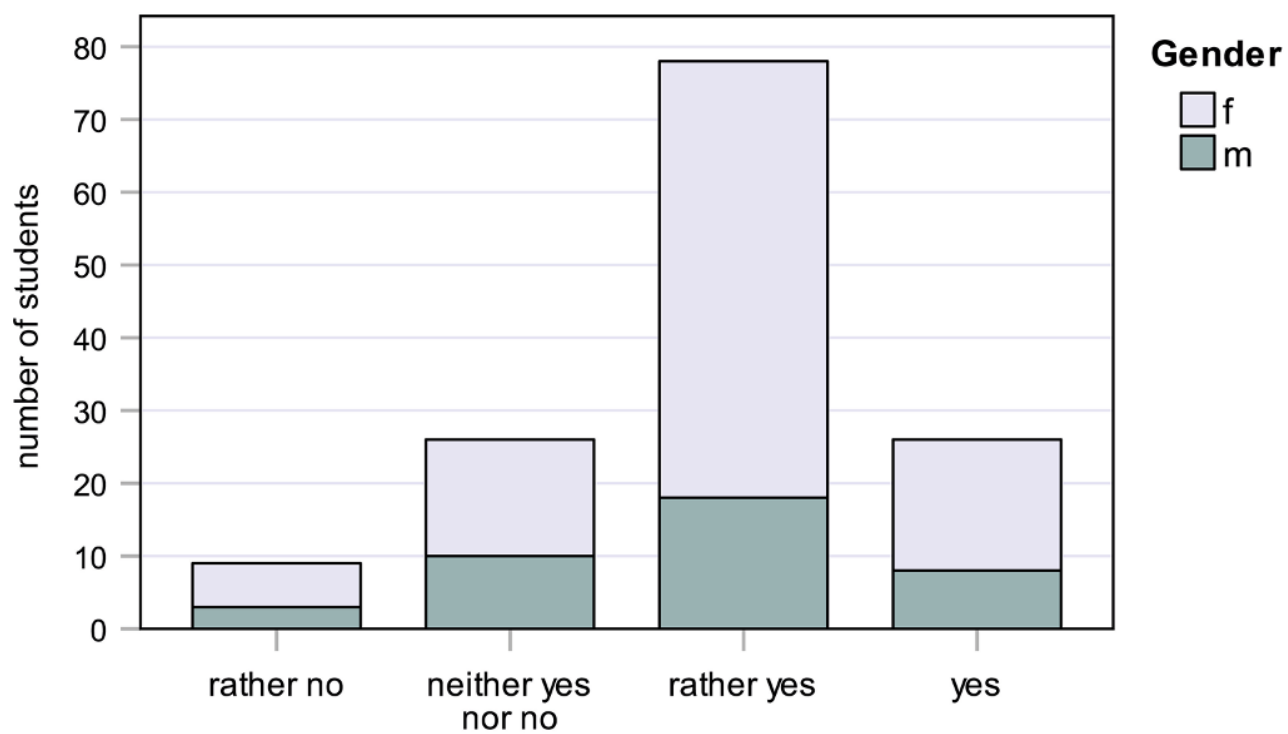

Were you able to follow the details of the surgical interventions?

$18.0 \%$ of female students and $20.5 \%$ of male students said "yes," while $60.0 \%$ of female students and $46.2 \%$ of male students said "rather yes." None of the students said they were unable to follow the surgical interventions (Fig. 2).

Question 3: How high was your interest in a professional career in surgery before the congress?

$14.0 \%$ of female students and $25.6 \%$ of male students had had "very high" interest, while $19.0 \%$ of female students and $20.5 \%$ of male students had had "low" interest (Fig. 3).

Question 4: How high was your interest in a professional career in surgery after the congress?
$16.0 \%$ of female students and $31.6 \%$ of male students had "very high" interest, while $9.0 \%$ of female students and $7.9 \%$ of male students had "low" interest (Fig. 4).

Question 5: How highly do you rate the educational gains of participating in a clinical congress as a medical student?

$22.0 \%$ of female students and $30.8 \%$ of male students said "very high," while $45.0 \%$ of female students and $59.0 \%$ of male students said "rather high" (Fig. 5).

Question 6: Should the participation of medical students in clinical congresses be an integral part of the medical curriculum?

Fig. 3 Responses to question 3: How high was your interest in a professional career in surgery before the congress?

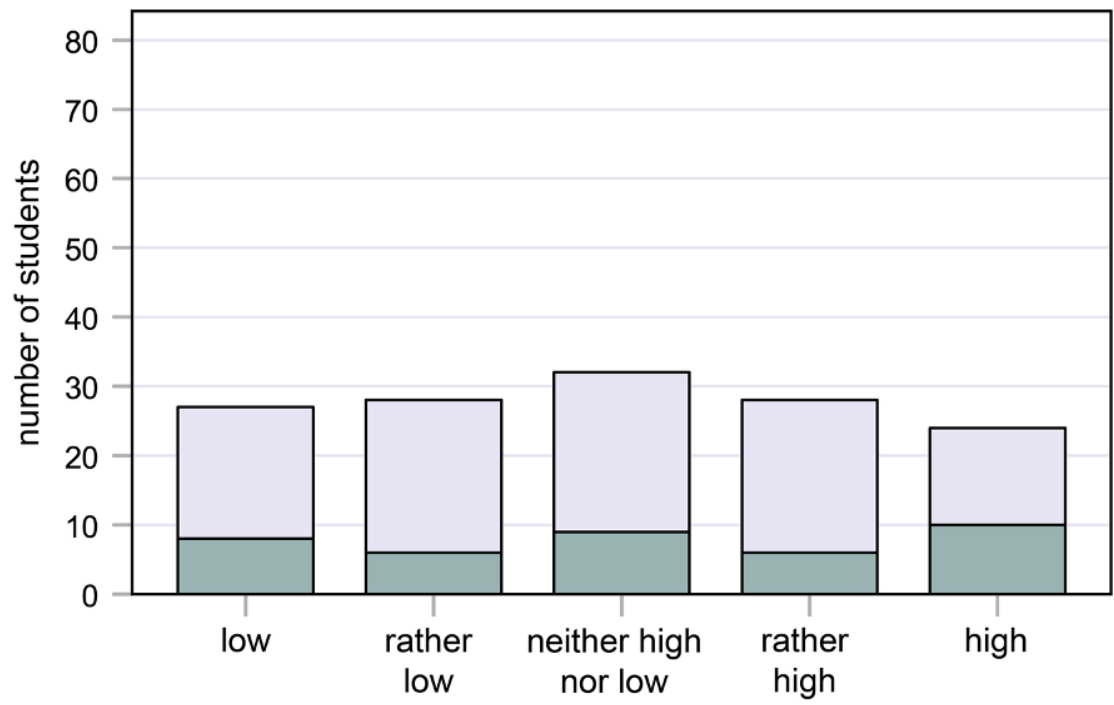

Gender

How high was your interest in a professional career in surgery before the congress? 
Fig. 4 Responses to question 4: How high was your interest in a professional career in surgery after the congress?

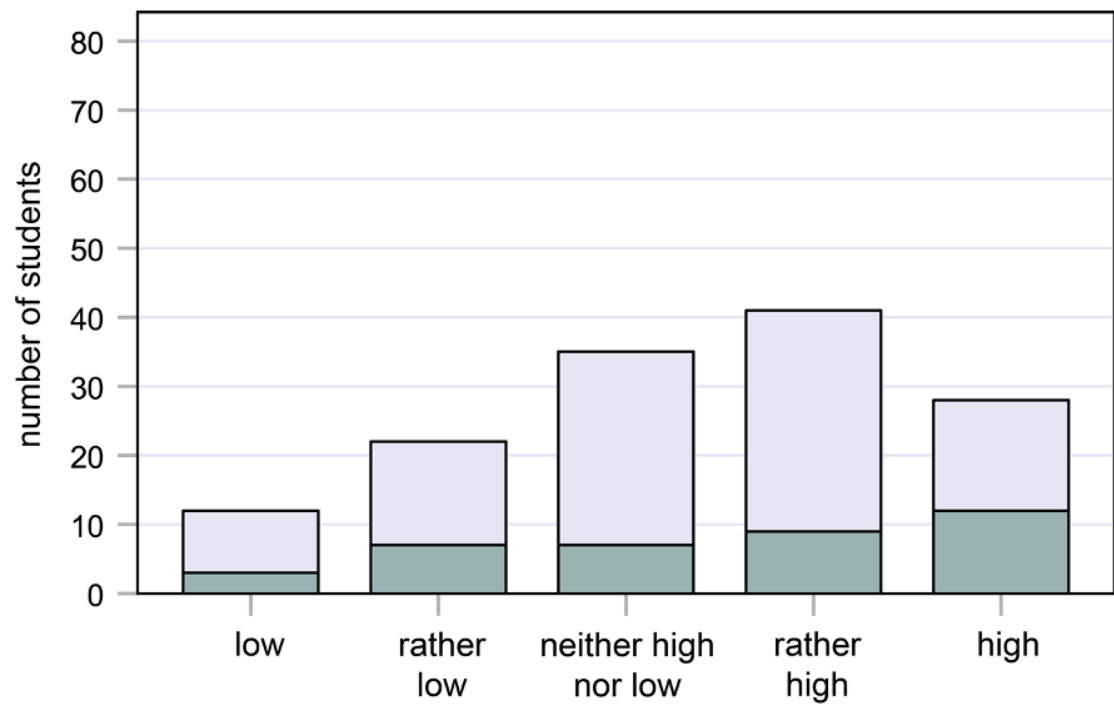

Gender

How high was your interest in a professional career in surgery after the congress?

Fig. 5 Responses to question 5: How highly do you rate the educational gains of participating in a clinical congress as a medical student?

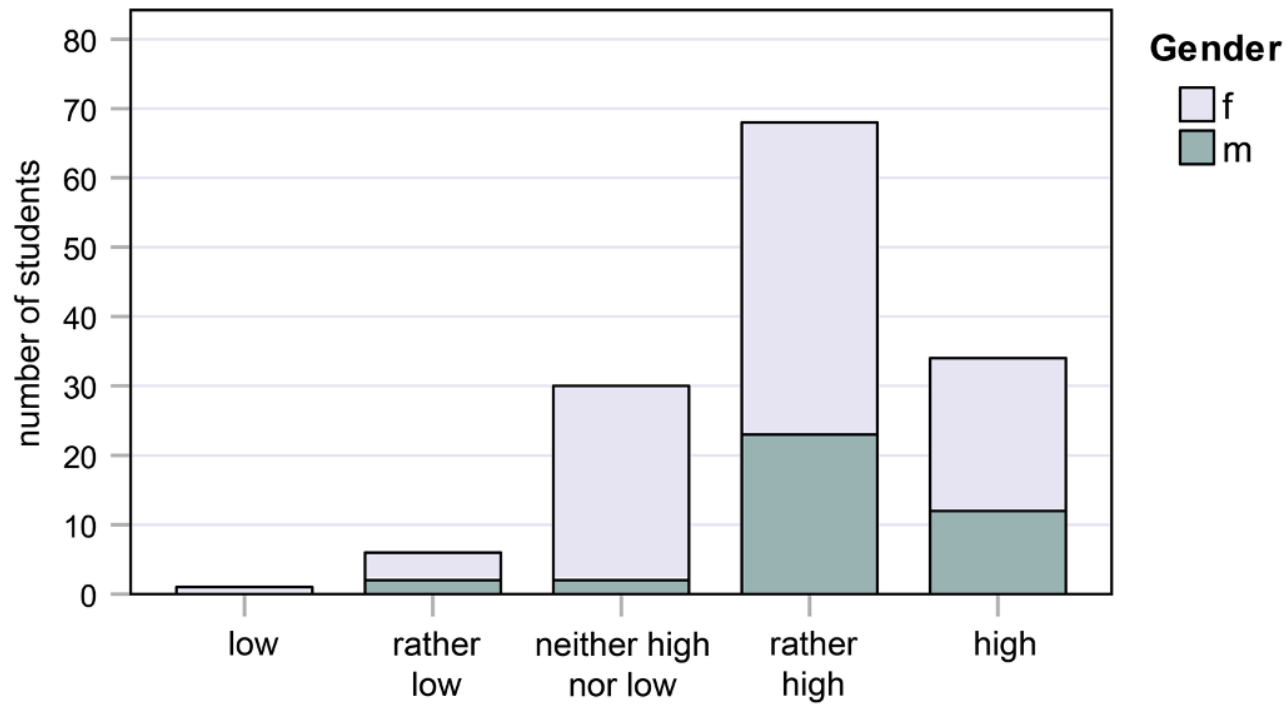

How highly do you rate the educational gains of participating in a clinical congress as a medical student?

$38.0 \%$ of female students and $41.0 \%$ of male students said "yes," while $34.0 \%$ of female students and $43.6 \%$ of male students said "rather yes" (Fig. 6).

A summary of the answers to all questions is shown in Fig. 7.

\section{Influence of gender, age, and previous vocational training}

The answers to all questions were analyzed with regard to the influence of gender, age, and previous vocational training. The influence of gender was only statistically significant ( $p=0.041$ ) for question 5 (How highly do you rate the educational gains of participating in a clinical congress as a medical student?). $89.8 \%$ of male students and $67.0 \%$ of female students rated the didactic gain very high and rather high, whereas $28.0 \%$ of female students and only $5.1 \%$ of male students said it was neither high nor low. No statistically significant difference was registered with regard to age (Kruskal-Wallis, $p \geq 0.05$ ).

Comparison of the answers of students with and without previous vocational training revealed no statistically significant difference (chi-square test on linear trend, $p \geq 0.05$ ). For a subgroup analysis, the students were divided into four groups: no vocational training (64.1\%); hospital/scrub nurses (16.2\%); emergency medical assistants (11.3\%); medical, laboratory, biological, or pharmaceutical assistants $(8.4 \%)$. Again, the answers were similar in all subgroups. Tests of 
Fig. 6 Responses to question 6: Should the participation of medical students in clinical congresses be an integral part of the medical curriculum?

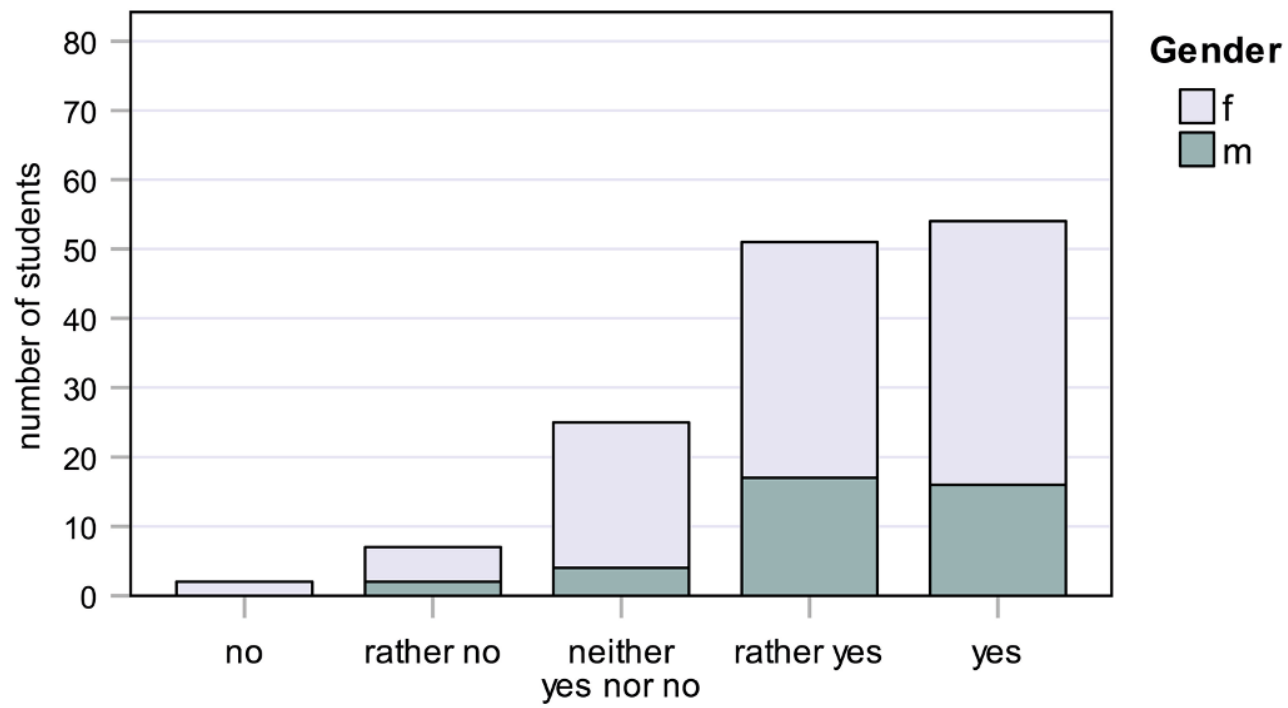

Should the participation of medical students in clinical congresses be an integral part of the medical curriculum?

Fig. 7 Summary of the answering behavior to questions 1-6

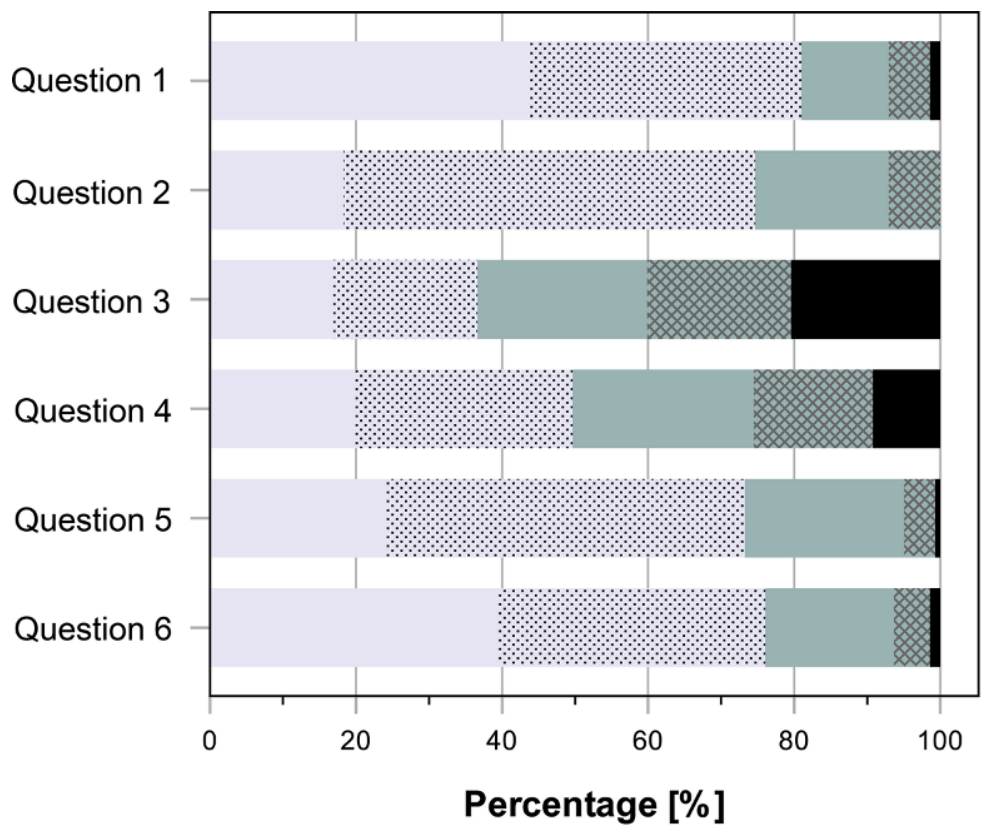

no/low

rather no/rather low neither yes nor no neither low nor high

rather yes/rather high yes/high significance could not be performed because of the small numbers in each group and the large number of answering options. Thus, no correlation was established between answering behavior and educational background.

\section{Interest in a professional career in surgery before and after the congress}

The students' interest in a professional career in surgery was evaluated before and after the congress (questions 3 and 4) and analyzed by a cross table (Fig. 8). While $37.6 \%$ of students had greater interest, $60.3 \%$ reported no change, and $2.1 \%$ reported less interest than before. The change in responses between question 3 and 4 was significant (Bowker symmetry test, $p<0.001)$.

\section{Free-text evaluation of the teaching project}

Finally, the students had the opportunity to evaluate the congress in free-text fields. They could express praise, criticism, and suggestions for improvement. The participants appreciated their active involvement in congress activities and the respect given to them by the surgical community. Their learning motivation and fascination for surgical disciplines were enhanced by the experience. On the other hand, owing to their limited knowledge, some attendees found it difficult to follow all surgical interventions and fully 


\begin{tabular}{|c|c|c|c|c|c|c|c|c|}
\hline & & & \multicolumn{5}{|c|}{ Question 4} & \multirow[t]{2}{*}{ total } \\
\hline & & & low & $\begin{array}{l}\text { rather } \\
\text { low }\end{array}$ & $\begin{array}{l}\text { neither high } \\
\text { nor low }\end{array}$ & $\begin{array}{l}\text { rather } \\
\text { high }\end{array}$ & high & \\
\hline \multirow[t]{10}{*}{ Question 3} & \multirow[t]{2}{*}{ low } & Number & 11 & 11 & 6 & 1 & 0 & 29 \\
\hline & & $\%$ of total number & $7.8 \%$ & $7.8 \%$ & $4.3 \%$ & $0.7 \%$ & $0.0 \%$ & $20.6 \%$ \\
\hline & \multirow[t]{2}{*}{ rather low } & Number & 0 & 12 & 13 & 3 & 0 & 28 \\
\hline & & $\%$ of total number & $0.0 \%$ & $8.5 \%$ & $9.2 \%$ & $2.1 \%$ & $0.0 \%$ & $19.9 \%$ \\
\hline & \multirow{2}{*}{$\begin{array}{l}\text { neither high } \\
\text { nor low }\end{array}$} & Number & 2 & 0 & 15 & 15 & 0 & 32 \\
\hline & & $\%$ of total number & $1.4 \%$ & $0.0 \%$ & $10.6 \%$ & $10.6 \%$ & $0.0 \%$ & $22.7 \%$ \\
\hline & \multirow[t]{2}{*}{ rather high } & Number & 0 & 0 & 1 & 23 & 4 & 28 \\
\hline & & $\%$ of total number & $0.0 \%$ & $0.0 \%$ & $0.7 \%$ & $16.3 \%$ & $2.8 \%$ & $19.9 \%$ \\
\hline & \multirow[t]{2}{*}{ very high } & Number & 0 & 0 & 0 & 0 & 24 & 24 \\
\hline & & $\%$ of total number & $0.0 \%$ & $0.0 \%$ & $0.0 \%$ & $0.0 \%$ & $17.0 \%$ & $17.0 \%$ \\
\hline & \multirow[b]{2}{*}{ total } & Number & 13 & 23 & 35 & 42 & 28 & 141 \\
\hline & & $\%$ of total number & $9.2 \%$ & $16.3 \%$ & $24.8 \%$ & $29.8 \%$ & $19.9 \%$ & $100.0 \%$ \\
\hline
\end{tabular}

Fig. 8 Interest in a professional career in surgery before and after the congress. Changes in response behavior concerning the interest in a professional career in surgery before (question 3) and after (question 4) the congress. The green fields

understand the diverse procedures. The students suggested a more detailed introduction to the clinical topics and surgical techniques presented at the congress, and adaptation of their own teaching modules to the contents of the congress. A summary of the most common free-text comments is given in Table 1.

\section{Discussion}

For the first time, medical students of the second academic year at the end of their preclinical period were given the opportunity to participate in a surgical congress. The congress was the 11th symposium of the German Society for Robot-Assisted Urology (Deutsche Gesellschaft für Roboter-assistierte Urologie e.V., DRUS), and simultaneously the first interdisciplinary symposium for robot-assisted and digital surgery in urology, gynecology, and visceral surgery in indicate a change towards "high" (37.6\%), the yellow fields indicate no change $(60.3 \%)$, and the red fields indicate a change towards "low" (2.1\%). The change in response behavior was significant (Bowker symmetry test, $p<0.001$ )

Germany. As the surgical regions of interest presented at the congress fitted well with the anatomy lectures and dissection courses in macroscopic anatomy, the students were expected to gain valuable information about the importance of applied anatomy [8] for their clinical study period, and also about current technical innovations in minimally invasive surgery.

If the participation of medical students in a surgical congress is to be included in the curriculum as a matter of principle, one would first have to think about the funding. In our example, participation was free of charge. One consideration would be to involve the students financially to a small extent in the participation in the congress. In addition, the medical faculty, but also the participating clinics that host the congress, could share the costs. Another consideration would be to include the sponsors of the congress in the participation costs.

\section{Table 1 Free-text comments}

\begin{tabular}{|c|c|c|}
\hline $\begin{array}{l}\text { What did you particularly like about this teaching } \\
\text { project? }\end{array}$ & What did you not like about the teaching project? & What would you improve in this teaching project? \\
\hline $\begin{array}{l}\text { Most common notions: } \\
\text { - Respect, appreciation, and the involvement of } \\
\text { students }(31.5 \%) \\
\text { - Motivation for enhanced learning activity due to } \\
\text { practical relevance }(19.6 \%) \\
\text { - No comment }(31.5 \%)\end{array}$ & $\begin{array}{l}\text { Most common notions: } \\
\text { - Lack of understanding of the content or subject } \\
\quad(7.0 \%) \\
\text { - No comment }(58.0 \%)\end{array}$ & $\begin{array}{l}\text { Most common notions: } \\
\text { - Adaptation to the current teaching curriculum } \\
\text { (21.7\%) } \\
\text { - Preparatory module for the contents of the } \\
\text { congress in advance }(14.0 \%) \\
\text { - No comment }(51.7 \%)\end{array}$ \\
\hline $\begin{array}{l}\text { Representative quotations: } \\
\text { - "Doctors took time to explain anatomical struc- } \\
\text { tures explicitly to the students." } \\
\text { _ "A lot of motivation to learn anatomy." } \\
\text { - "I got insights into areas that were not ad- } \\
\text { dressed during my preclinical studies." } \\
\text { _ "More fascination for surgery." }\end{array}$ & $\begin{array}{l}\text { Representative quotations: } \\
\text { _ "The idea of students participating in the } \\
\text { congress is good, but currently we are not in- } \\
\text { volved in the topics discussed." } \\
\text { _ "Too many changes of surgical interventions and } \\
\text { topographic regions." } \\
\text { _ "I could not follow so well because of my limited } \\
\text { knowledge." }\end{array}$ & $\begin{array}{l}\text { Representative quotations: } \\
\text { - "The topics of the congress should fit with the } \\
\text { teaching curriculum for easier consolidation of } \\
\text { what has been learned." } \\
\text { _ "The spectrum of surgical techniques shown at } \\
\text { the congress should be explained in advance." } \\
\text { _ "More time for preparation." }\end{array}$ \\
\hline
\end{tabular}


Although the study has considered many issues, there are some limitations worth mentioning: It would be interesting to investigate which medical specialty the students actually choose after graduation. Has it really become a surgical subject, as perhaps indicated on the questionnaire? For such an analysis, however, much more time would have to have passed, so that even then the congress would lose its topicality.

Another interesting starting point would be a modified study design in the sense of a case-control study. For example, one could investigate whether the medical specialty of congress participants differs from that of those who did not participate in a surgical congress.

Due to the strict separation of the preclinical and clinical study sections, preclinical medical students are largely unaware of the practical relevance of their theoretical knowledge. Although learning anatomy by means of lectures, textbooks, and dissection courses provides a basic understanding of the subject, these approaches are far removed from the clinical context and clinical applications. This didactic gap is particularly true for surgical disciplines and may result in a general lack of learning motivation as well as a specific lack of interest in pursuing a career in surgery.

\section{Interest in a career in surgery}

Confronted with a declining number of applicants for general surgery programs, a study group in Texas [4] analyzed the factors that influence the career choice of medical students. One-hundred and eleven medical students in their fourth year of medical school participated in the study and ranked 18 items on a scale from 1 (not important) to 8 (very important). The factors were: career opportunities, academic opportunities, experience in core rotation/sub-internship, role model(s) in that specialty (mentors), length of training required, lifestyle during residency, work hours during residency, ability to obtain a residency position, concern about loans/debts, call schedule, lifestyle after training, work hours after training, financial rewards after training, intellectual challenge, patient relationships/interaction, prestige, future patient demographics, and gender distribution in the specialty. Only $17.1 \%$ students were interested in pursuing a surgical career because of career opportunities $(p<0.04)$ and prestige $(p<0.003)$. In contrast, lifestyle during residency $(p<0.0007)$, work hours during residency $(p<0.008)$, and the quality of the patient/physician relationship $(p<0.05)$ were all significantly negatively correlated with the choice of a career in surgery [4].

Schmidt et al. [9] analyzed six electronic databases concerning the current published literature about US medical students' experience in surgery and the factors influencing their intention to pursue surgery as a career. The authors concluded that early introduction to surgery as well as recruitment strategies during the preclinical and clinical years of medical school are liable to substantially enhance the students' interest in a surgical career [9].

These observations are in conformity with the results of our teaching project. Early introduction to surgical procedures during the preclinical period of medical school in the form of active participation in a congress culminated in greater interest in a subsequent surgical career. Comparison of the response behavior before and after the congress revealed that significantly more students would opt for a career in surgery after having attended the congress $(p<0.001)$.

\section{Enhanced learning motivation}

The congress was focused on specific anatomical regions (pelvis, retroperitoneum), which were addressed by visceral surgeons, urologists, and gynecologists via video sessions and live surgeries. This interdisciplinary platform provided optimal first-hand impressions of clinically relevant aspects of anatomy, thus bridging the gap between theoretical knowledge and practical application. Subsequently, the students were more motivated to learn anatomy: $45.0 \%$ of female students and $43.6 \%$ of male students said "yes" to this question; $34.0 \%$ of female students and $41 \%$ of male students said "rather yes."

In addition to live surgeries, medical students were invited to become familiar with virtual training devices and surgical simulators, which were presented during the congress to demonstrate and practice surgical processes and management [10-12]. The rationale for an early confrontation with these training tools was the observation that students using these devices in their medical curriculum were highly motivated, grasped the procedures rapidly, and became exceptionally skilled in the practical use of minimally invasive techniques [13].

\section{Role of gender in opting for a career in surgery}

The percentage of female medical students has increased significantly throughout the world over the past decade [14]. This demographic shift is expected to considerably change not only the proportion of male versus female physicians, but also their respective medical careers of choice. A large-scale study from the Royal College of Surgeons in Ireland (RCSI) [15] analyzed the differences between male and female students' perceptions of a surgical career. The results of the questionnaire (464 students, $40 \%$ males vs. $60 \%$ females) indicated that male students were significantly more influenced by remuneration than females $(p<0.001)$. In contrast, female students were significantly more influenced by part-time work $(p<0.001)$, parental leave $(p<0.001)$, working hours $(p<0.001)$, and length of residency $(p=0.003)$. The authors noted that the preference for a career in surgery declines with advancing academic years in medical school among male as well as female stu- 
dents. Medical students reported intense feelings of intimidation or being ignored during their surgical internships. Consequently, their enthusiasm for surgical disciplines declines consistently during their exposure to surgical practice. These findings, along with the importance of role modeling, underline the urgent need to address those factors that make surgery less appealing, especially to female medical graduates [15].

Chiu et al. [14] analyzed another interesting aspect of gender-specific differences: putative gender differences of medical students related to the acquisition of robotic suturing skills were examined. The students underwent a two-step DaVinci training; their performance was evaluated and compared. Female medical students performed significantly better in the virtual reality task of using a skin suturing pad and were able to complete more sutures with the robotic system than male students. However, no gender difference was noted with regard to the quality of the robotic suture [14].

The gender proportion in our study (98 females vs. 39 males, $2.5: 1$ ) confirms the general observation that the number of female medical students is twoto threefold higher than male medical students. However, when the results of the questionnaire were compared with regard to gender, a significant difference $(p=0.041)$ was only registered for question 5 ("How highly do you rate the educational gains of participating in a clinical congress as a medical student?"). While $22 \%$ of female students and $30.8 \%$ of male students said "very high," $45 \%$ of female students and $59 \%$ of male students said "rather high," suggesting that male students were more convinced about the educational benefit of the congress.

\section{Role of the generation shift in opting for a career in surgery}

The steadily declining interest in pursuing a career in surgery appears to be related to the generation shift in favor of the currently dominant generations $\mathrm{Y}$ and $\mathrm{Z}$, whose major focus is not surgery. Social sciences have divided the five living generations into the "builders," "baby boomers," and the respective generations " $\mathrm{X}, \mathrm{Y}$, and Z" [16]. Generation Y consists of persons born between 1980 and 1995 [17]. According to the data of the Federal Statistical Office published in 2015, about $22 \%$ of the total population and $20 \%$ of the workforce in Germany were born between 1980 and 1999 [18]. Generation Y is believed to be predominantly well educated, and their relatives frequently have a university degree. They prefer to work in teams than in strong hierarchies and consider the joy of work more important than status or prestige. More freedom of choice, the opportunity of self-fulfillment, and more time for family and leisure are the prime demands of generation Y [19]; they do not wish to subordinate everything else in their lives to their professional career, but strive for a work-life balance and a meaningful job [20]. These attitudes are in stark contrast to the circumstances in most surgical disciplines. The workload in surgical disciplines is far in excess of those envisioned by generation $\mathrm{Y}$.

Lafraira et al. [21] performed a study to evaluate current attitudes, experiences, and expectations of residents belonging to the generation $\mathrm{Y}$ in surgical fields. One half of the residents were satisfied with the residency program. However, the proportion of dissatisfied reached $40 \%$ with regard to the number of surgical interventions, and $80 \%$ with regard to professional mentorship. Thus, $62 \%$ of the residents were not confident about performing operations after their residency. The authors conclude that current residents are less satisfied with their job and more critical of the quality of training and teaching. These altered attitudes match the profile of generation $\mathrm{Y}$, which is more iconoclastic than previous generations [21].

A study from Germany [3] included 1098 medical students in a survey to gain insights into the mechanisms underlying the decision in favor of or against a career in surgery. The majority of students were of the opinion that surgery is an interesting and meaningful profession. However, the majority of the students $(89 \%$ females, $81 \%$ males) were unwilling to choose a surgical specialty. While the students are certainly willing to spend a large amount of time on their professional lives, they demand the option of being able to plan their lives and achieve a satisfactory work-life balance. Flexible working hours and an existing childcare program were identified as predominant factors for all students, especially females. Prestige and salary were less relevant than "self-fulfillment" in terms of respectful interaction and a wellbalanced professional and private life [3].

The present study did not focus in detail on the pros and cons raised by medical students concerning a career in surgery. However, the data retrieved from the questionnaire confirmed that medical students belonging to generation $\mathrm{Y}$ are not primarily interested in a time-consuming surgical career. While $37.4 \%$ and $39.5 \%$ of medical students had low/rather low interest, respectively, $23 \%$ were still undecided. However, active involvement in a surgically oriented congress obviously increased the students' overall interest in opting for a professional career in surgical disciplines, including those belonging to generation $\mathrm{Y}$.

\section{Conclusion}

Apparently, learning motivation as well as the interest in a surgical career among medical students can be positively influenced during the early phase of their medical studies. Participation in a surgery congress had a twofold effect. On the one hand, the missing connection between the preclinical and clinical study period could be bridged by highlighting the practical clinical applications of the theoretical knowledge ac- 
quired by the students during their preclinical study period. On the other hand, the congress provided early insights into the tasks, challenges, and professional gains of a surgical profession, and thus established a realistic foundation for subsequent decisions concerning a medical subspecialty. The congress spanned a number of surgical disciplines, a large spectrum of live surgeries, and interactive training devices; this was considered especially suitable to provide large-scale multidimensional impressions of modern surgical practice [13].

It may be assumed that the stimulating experience of being directly involved in a surgical congress may not only increase the students' learning motivation during medical school, but also their motivation to consider a career in surgery. At best, the enthusiasm induced by direct exposure to the fascinating aspects of surgical work is able to change the attitude of the current generation $\mathrm{Y}$ towards their later professional life and their willingness to face the required effort and tasks.

Moreover, medical faculties could be encouraged by the experiences gained in this pilot teaching project to incorporate the participation of medical students in medical congresses as an integral part of the curriculum. In particular, surgical societies should provide more options for medical students to take part in symposia, training workshops, and congresses. This would provide young academics with valuable insights into the spectrum of technical innovations and subspecialties. The motivation of the current and next generation to pursue a career in surgery against all odds will be achieved best by offering convincing reasons.

Acknowledgements We thank Ulrike von Hehn from medistat.de for statistical analysis. Further we thankDr. Ole Christan Leuth for the digital image editing.

Funding We thank the Medical Faculty of Kiel University for their financial support of this innovative teaching project. The Medical Faculty of Kiel University funded this pilot teaching project with $4000 €$, to enable medical students to attend the congress for one day free of charge.

Author Contribution Ibrahim Alkatout: project development, congress organizer, data analysis, writing of manuscript, editing; Veronika Günther: data analysis, writing of manuscript, editing; Sandra Brügge: project development; Johannes Ackermann: project development, data analysis; Magret Krüger: project development, data analysis; Dirk Bauerschlag: project development, congress organizer; Nicolai Maass: project development, congress organizer; Sebastian Lippross: project development; Ingolf Cascorbi: project development; JanHendrik Egberts: project development, congress organizer; Thomas Becker: project development, congress organizer; Daniar Osmonov: project development, congress organizer; Klaus-Peter Jünemann: project development, congress organizer; Thilo Wedel: project development, congress organizer, data analysis, writing of manuscript, editing

Funding Open Access funding enabled and organized by Projekt DEAL.

\section{Compliance with ethical guidelines}

Conflict of interest I. Alkatout, V. Günther, S. Brügge, J. Ackermann, M. Krüger, D. Bauerschlag, N. Maass, S. Lippross, I. Cascorbi, J.-H. Egberts, T. Becker, D. Osmonov, K.-P. Jünemann, and T. Wedel declare that they have no competing interests.

Ethical standards All procedures performed in studies involving human participants or on human tissue were in accordance with the ethical standards of the institutional and/or national research committee and with the 1975 Helsinki declaration and its later amendments or comparable ethical standards. The Ethics Committee of the Medical Faculty of Kiel University (Arnold-Heller-Str., House 9, 24105 Kiel, Germany) gave its positive vote (D 453/18). Informed consent was obtained from all individual participants included in the study.

Open Access This article is licensed under a Creative Commons Attribution 4.0 International License, which permits use, sharing, adaptation, distribution and reproduction in any medium or format, as long as you give appropriate credit to the original author(s) and the source, provide a link to the Creative Commons licence, and indicate if changes were made. The images or other third party material in this article are included in the article's Creative Commons licence, unless indicated otherwise in a credit line to the material. If material is not included in the article's Creative Commons licence and your intended use is not permitted by statutory regulation or exceeds the permitted use, you will need to obtain permission directly from the copyright holder. To view a copy of this licence, visit http://creativecommons.org/licenses/by/4.0/.

\section{References}

1. Occam Education. Medical School: the US or the UK? 2019. https://occameducation.com/what-are-the-differencesbetween-medical-schools-in-the-us-and-the-uk/. Accessed 10 July 2020.

2. Alkatout I, et al. Abdominal anatomy in the context of port placement and trocars. J Turk Ger Gynecol Assoc. 2015;16(4):241-51.

3. Kleinert $\mathrm{R}$, et al. Generation $\mathrm{Y}$ and surgical residency-passing the baton or the end of the world as we know it? Results from a survey among medical students in Germany. Plos One. 2017;12(11):e188114.

4. Azizzadeh A, et al. Factors influencing career choice among medical students interested in surgery. Curr Surg. 2003;60(2):210-3.

5. Aselmann H, et al. Robotic-assisted total mesorectal excision (TME) for rectal cancer results in a significantly higher quality of TME specimen compared to the laparoscopic approach-report of a single-center experience. IntJColorectal Dis. 2018;33(11):1575-81.

6. Schollmeyer T, et al. Hysterectomy trends over a 9-year period in an endoscopic teaching center. Int J Gynaecol Obstet. 2014;126(1):45-9.

7. Alkatout I, Holthaus B. Congress report of the 23(rd) AGE annual meeting from 26(th) -28(th) April 2018 in Hamburg. J Turk Ger Gynecol Assoc. 2018in;19(3):176-81.

8. Stelzner S, et al. Anatomy of the transverse colon revisited with respect to complete mesocolic excision and possible pathways of aberrant lymphatic tumor spread. Int J Colorectal Dis. 2016;31(2):377-84.

9. Schmidt LE, Cooper CA, Guo WA. Factors influencing US medical students' decision to pursue surgery. J Surg Res. 2016;203(1):64-74. 
10. Elessawy M, et al. Integration and validation of hysteroscopy simulation in the surgical training curriculum. JSurg Educ. 2017;74(1):84-90.

11. Elessawy M, et al. Validation of psychomotor tasks by Simbionix LAP Mentor simulator and identifying the target group. Minim Invasive Ther Allied Technol. 2017;26(5):262-8.

12. Osmonov DK, et al. Surgical site infections after radical prostatectomy: a comparative study between robot-assisted laparoscopic radical prostatectomy and retropubic radical prostatectomy. TurkJ Urol. 2018;44(4):303-10.

13. Spille J, et al. 2D versus $3 \mathrm{D}$ in laparoscopic surgery by beginners and experts: a randomized controlled trial on a Pelvitrainer in objectively graded surgical steps. J Surg Educ. 2017;74(5):867-77.

14. Chiu HY, et al. Gender differences in the acquisition of suturing skills with the da Vinci surgical system. J Formos Med Assoc. 2020;119(1 Pt3):462-70.
15. Cronin C, et al. Are we reaping what we sow? Gender diversity in surgery: a survey of medical students. Postgrad Med J.2019;95(1121):119-24.

16. Mitchell DA. Generation Z-striking the balance: healthy doctors for a healthy community. Aust Fam Physician. 2008;37(8):665-7.

17. Carrington C. Why are Millennials worried about the future? ABC News. 2017.

18. Destatis. Bevölkerungspyramide 2015.2017.

19. Schlitzkus LL, Schenarts KD, Schenarts PJ. Is your residency program ready for Generation Y? J Surg Educ. 2010;67(2):108-11.

20. Bund K. Wir sind jung ... und brauchen das Glück. Zeit Online. 2014.

21. Lafraia FM, et al. Attitudes and experiences during training and professional expectations in generation-y surgical residents. RevAssoc Med Bras. 2019;65(3):348-54.

Publisher's Note Springer Nature remains neutral with regard to jurisdictional claims in published maps and institutional affiliations. 